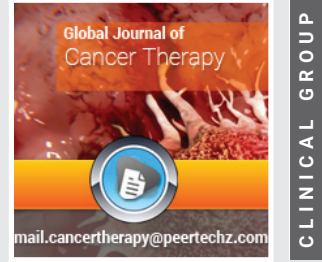

\title{
Application of nano based drug delivery channel against leukemia chemotherapeutic
} resistance

Received: 21 January, 2021

Accepted: 04 February, 2021

Published: 09 February, 2021

*Corresponding author: Rahul Bhattacharjee, Kiit School of Biotechnology, Bhubanewar, Odisha, India, E-mail: 1660114@kiitbiotech.ac.in; rahuljonty0798@ gmail.com

Keywords: Cancer; Leukemia; Chemotherapy; Drug delivery and Gold nanoparticles

https://www. peertechz.com

\section{Check for updates}

\author{
Rahul Bhattacharjee ${ }^{1 *}$, Olabimtan Olabode $\mathrm{H}^{2}$, Ochigbo \\ Victor $^{3}$ and Samuel Florence ${ }^{3}$ \\ ${ }^{1}$ Kiit School of Biotechnology, Bhubanewar, Odisha, India \\ ${ }^{2}$ Department of Industrial and Environmental Pollution, National Research Institute for Chemical \\ Technology Zaria Kaduna State, Nigeria. \\ ${ }^{3}$ Department of Scientific and Industrial Research, National Research Institute for Chemical \\ Technology, Zaria KadunaState, Nigeria
}

\begin{abstract}
To the management of leukemia, traditional chemotherapy is characterized by repeated dosage, adverse side effects, disruption to the immune system and other organs with rapidly proliferating cells due to non-specific targeting, insolubility, and failure to attack the tumor center, low survival treatment impairments, and resistance from the targeted cancerous cells. The management of most anti-leukemic drugs would be improved if, through a suitable scientific process that can be released to their biological targets through technological manipulation at the nano-molecular dimension. Nanoparticles are increasingly being implemented and adopted in alleviating numerous constraints with the conventional technique for drug delivery with cancer therapy. With excessive drug localization and cell adhesion, nanotechnology has presented an opportunity to selectively secure easy links to cancerous cells as it is feasible to program nanoparticles such as gold to identify cancerous cells as well as provide selective and precise drug delivery mechanisms that prevent interplay with normal cells. This review outlook essentially illustrates the significance of nano-based anticancer therapy for active targeting, the drawbacks of traditional chemotherapy, the responsive pH existence of nano-based anticancer drugs with cellular delivery through a stabilized biocompatible carrier, the biochemical compositions of nano-structured media, existing methodologies for nano-based anticancer therapy (leukemia) formulation and recognition of gold nanoparticles as an ideal anticancer drug delivery material.
\end{abstract}

\section{Introduction}

Leukemiahas been modern time's most devastating diseases, killing millions every year. This has been the twentiethcentury health challenges without limits against a human with the unregulated proliferation of the cancerous cells with a very complex treatment process [1]. This demonstrates diagnostic variance with treatment resistance due to the complexity of the phenotypic and genetic frameworks [1]. Treatment of cancer in any form has attracted several therapies with certain specified disadvantages and adverse impacts with the emergence of resistance to chemotherapy [2]. Limited FDA-approved drugs tackle leukemia cancer cells actively, triggering recurrences that are resistant to treatment as transplantation with the stem cell is the only recognized therapy that counters their activity
[2]. Anti-cancer drugs are administered clinically to patients through chemotherapy, a routine procedure, to neutralize cell proliferation alongside surgical elimination, hormone, and radiation therapy. (Sutradhar \& Amin, 2014) [2] Meanwhile, several complications occur with the unspecified targeting by anticancer drugs, and negative drug distribution system [2]. As the formulation of cancer chemotherapy drugs requires a complex process that is attributed to highly developed polymer chemistry and electronic engineering [2]. However, the key task is to extricate cancer cells from the regular cells within the body systems and to develop the drug in a manner that cancerous cells can be detected and inhibit differentiation and replication. Unfortunately, modern chemotherapies have failed to selectively exterminate cancer cells without disrupting normal cells of the body with severe adverse effects with organ 
failure, leading to poor care at low therapeutic doses with eventual death [3]. Characterized by the presence of this type of cancer, leukemia poses particular treatment challenges as bone marrow, which creates blood cells, is impaired by the condition. Leukemia is a premature blood-generating stem cell growth characterized as cancer of the white blood cells [1]. Chemotherapy is the first phase of therapies to disrupt cancerous white blood cells, but if the leukemia stem cells within the marrow of the bone survive, they can recur in a form resistant to therapy. Under $20 \%$ of children and up to two-thirds of older patients with leukemia report a relapse as adults with relapse experience a survival rate of less than 30 percent, while the survival rate of five years posts relapse for children, is around two thirds [4]. Chemotherapy would not boost the response to treatment for these patients if a relapse occurs as to why scientists have a pressing necessity to design a treatment that can attack chemotherapy-resistant cells more effectively [4].

A group of unusual Leukemia-Initiating Cells (LICs), that are cells prone to leukemic transition within the hematopoietic structure into more distinct blasts, is considered to be triggered by chemoresistance and acute leukemia relapse. LICs were first detected within the $\mathrm{CD} 34+\mathrm{CD} 38$ compartment in acute myeloid leukemia (AML) and were capable of activating mammalian AML in NOD/SCID mice. (D. Bonnet and J.E. Dick 1997). With stable hematopoietic stem cells, LICs share several properties (HSCs) as they are the only cells capable of creating all lineages of blood cells in life. [5] LICs are largely inactive and thus resist chemotherapeutic drugs that target cycling cells preferentially. (R. Fragoso, J.T. Barata,(2014). Also, LICs can auto-renew and produce more LICs with the capacity to separate into a progeny with limited capacity for self-renewal (D.A. Pollyea, et al 2014).HSCs cells retain the capacity for self-renewal within the hematopoietic system and are classified by rarely operating within a homeostatic environment. Due to the organization of normal hematopoiesis as a hierarchy, HSCs at the peak distinguished blood cells consistently. In general, the selfrenewal operation of HSCs preserves the scale of the HSC pool over time. (J. Seita and I.L. Weissman, 2010). In the meantime, the underlying mechanism may incorporate distorted membrane transportation with the multidrug resistance (MDR) gene P-glycoprotein compound with related proteins, modified targeting enzymes, regulated drug activity and drug inhibition due to conjugation with increased drug activation Aims to overcome resistance Specifically, combination drug therapy requires the use of various groups of drugs with mild overlapping adverse health effects that permit optimum dosage with the shortest periods for the regeneration of the bone marrow. The latest experimental methods are adjuvant therapy with P-glycoprotein inhibitors and, in particular cases, the use of growth factor and protein kinase $\mathrm{C}$ inhibitors, which relapse the resistance delay. An extra alternative to inhibiting the drug resistance genes could be gene deletion using antisense molecules. Conversely, by transplanting retrovirally transformed $\mathrm{CD} 34$ cells expressing the MDRR, drug resistance can also be used for good purposes with dosage chemotherapy (Y.A. Luqmani, 2005).
There are several limitations of chemotherapy. The disruption of the rapidly dividing cells, which is the key property of neoplastic cells is usually frustrated by typical chemotherapeutic agents as the reason why chemotherapy destroys bone marrow cells, healthy hair follicles, macrophages, and the digestive tract [6]. In other words, as they are not selective only to cancerous cells, they lead to known side effects like mucositis which is the inflammation of the gastrointestinal tract, myelosuppression that decreased the development of immunosuppression by white blood cells, alopecia, organ dysfunction, anemia, or thrombocytopenia, dose reduction and delay in treatment or discontinuation of treatment [7]. Cell division can be effectively prevented in the circumstance of solid tumors, causing chemotherapy drugs insensitive to treatment. Chemotherapeutic drugs are also unable to infiltrate the center of solid tumors with failure in destroying the cancerous cells [8]. Standard chemotherapeutics are frequently filtered out of the macrophage-engulfed circulation thus persist in the circulation for a short period with the inability to obstruct the cancer cells [7]. Similarly, poor solubility of the treatments is a big concern, allowing them not to traverse the biological layers [8] and the inability of chemotherapeutics drugs to penetrate the nucleus inside the cells as explained in Figure 1 [7]. P-glycoprotein, a multidrug resistance component that is overexpressed on the cell surface which inhibits the absorption of drugs behaves as an efflux pump that regulates the emergence of anticancer therapy resistance.

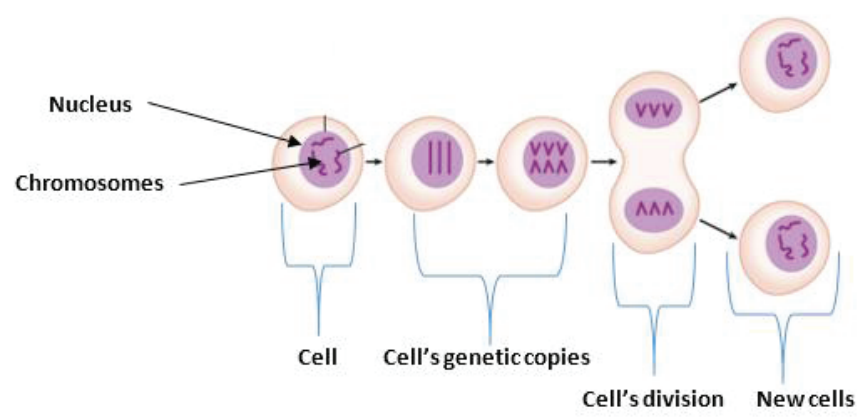

Figure 1: Chemotherapy damages the genes inside the nucleus of cells.

\section{Nanotechnology in cancer cells targeting}

The aspect of science that typically addresses the size range around several nanometers, designed for a specific application, is what nanotechnology is portraying [2]. Some years ago, the development of concise drug delivery applications has become an area of focus as it gives significant advantages to surmount the drawbacks of conventional chemotherapies [2]. Nano cancer therapy is very convincing both in diagnosis and treatment phases since it can penetrate tissues cellularly [2]. In other words, nanomedicine is now technically being evaluated and applied in cancer therapy reflecting a significant milestone in the identification, diagnosis, and control of the diseases. That is, drug delivery techniques with the approach of nanotechnology can drastically enhance detection sensitivity 
and stability of drug for combating multidrug resistance, particularly with solid tumors, as nanoparticles conveniently active due to their enhanced absorption coefficient and stabilization effect [9].

Different studies have been conducted to explore more precise treatment options with nanotechnology that mitigates the side effects of conventional chemotherapies (Sutradhar \& Amin, 2014) [2]. It has now been designed to help the targeted therapies navigate across biological membranes, activate molecular interactions, and recognize alterations in molecules. Particularly in comparison to macroparticles, they possess a huge surface area with configurable biological, optical, mechanical, and magnetic properties [2]. Recent drug delivery with metallic nanoparticles for cancer therapy encompasses polymeric micelles, nanospheres, dendrimers liposomes, nano-capsules, and nanotubes that are already marketed under Abraxane and DOXIL (liposomal doxorubicin) (albumin-bound paclitaxel) [2].

In the scenario of targeted delivery, nanoparticles infused with chemotherapy entities are formulated to react directly with the defective cells. Thus, the substrate of the nanoparticles is altered to tackle the cancer cells as targeting entities are affixed to the surface of nanoparticles for molecular definitions. They are attacked by engineered nanoparticles either by antibody-antigen recognition or ligand-receptor engagement [10]. Three main modules for a targeted delivery structure centered on nanotechnology are anticancer management with an inducing agent, targeted moiety-penetration mechanism, and a mobilizer. To develop a nanoparticle, materials such as polymers, ceramics, metals, and lipids are widely used materials [2]. And typically, synthetic and natural composites with lipids are utilized as vectors of drug delivery. Chemotherapy based particles are absorbed by phagocytic cells with easy clearance by the Reticuloendothelial Mechanism (RES) [2]. Arrays of procedures have been introduced to preserve nanoparticles within the bloodstream as the modification of the carrier's polymeric composition which is to prevent washing out and circulation in the blood system for a longer time frame as they are encapsulated by hydrophilic polymers that effectively target cancerous cells. Around the nanoparticle surface, hydrophilic polymer coating resists plasma proteins as they evade opsonization and washing (cloud effects) [11]. Polyethylene Glycol (PEG), polyoxins, poloxamers, and polysaccharides especially are frequently employed hydrophilic polymers [11]. At the molecular level, cancer cells have certain peculiar properties that distinguish them from healthy cells as certain receptors are been over-activated on their surfaces which distinguish the function. The Connection to the surface of nanoparticles with the corresponding ligands induces them to attack only cancer cells. As the nanoparticles entangle to the receptors, they actively allow receptor-mediated cell endocytosis or phagocytosis, culminating in encapsulated drug cell internalization [12].

Meanwhile, a successful targeted delivery system of drugs is linked with a mechanism that transports a certain quantity or both of a therapeutic or diagnostic agent to the defected organ within the body systems (Anarjan, 2019) [13]. Drug- loaded nanoparticles are employed in the identification of particular receptors/antigens on target cells by the addition of ligands or unique physical or chemical engineering structures due to limitations of non-specific drug delivery in whole body cells and decreasing cytotoxicity and adverse impacts of drugs on healthy cells and organs that are unlikely in conventional chemotherapy. Vehicles with intelligent nanoparticles have been licensed for the treatment of a wide range of human cancers [13].

The application of drug delivery can be divided into two criteria which are either active drug targeting which can be used for antibody, receptor, and carbohydrate, or passive drug targeting which can be used for direct use, oncolytic therapy and leaky vasculature as explained in the figure. Active drug delivery targeting also referred to as the ligand-mediated targeted strategy, requires identification, acquisition, and encourage acceptance by the targeted cells based on their affinities [14]. Various unique molecular interactions such as receptor-ligand-dependent attachments, charge-based interactions, and facilitated motif-based interactions with substrate molecules are based on chemical affinity for active targeting [15] A ligand may be various biomolecules, including antibodies, proteins, nucleic acids, peptides, carbohydrates, and tiny organic molecules such as vitamins [16]. Surface molecules released in diseased cells, proteins, sugars, or lipids present in the tissues, secreted tumor cells in the microenvironment of a cancer cell or with the local environment can be the target substrates [17]. Smart, targeted systems based on nanomaterials leverage the multivalent nature of ligands' interactions with the target antibodies There is an exponential rise in the exactness of nanoparticles for their cognate target [18] as several ligand molecules are accumulated in the nanosystems. In particular, the coupling of one ligand molecule usually promotes the interaction by coordinated actions of the resulting metabolites, significantly increasing the binding efficiency and subsequent behavior. With passive targeting, Intravenous administration is perhaps the most common delivery system for nanomaterial-based anticancer drugs. The absorption phase through the intestinal epithelium needed after oral administration is bypassed by this approach [19]. This deposition of the drug at the location of the tumor is a passive procedure that requires extended-release for adequate delivery of the drug. The accumulation of nanocarriers depends primarily on physicochemical characteristics such as scale, shape, surface characteristics, and chemistry [20].

The degrees of the aggregation of nanomaterials at the site of the tumor is dictated by their thickness. Nanocarriers have to be less to the dimension in the neovasculature, having the scale that acutely alters the extravasation of the tumor. Similarly, blood perfusion, passive interactions with biomolecules, and immunological clarifications affect the biodistribution of the nanomaterial-drug formulation [21].

Nanotechnology typically has the opportunity to overcome many limitations in traditional therapeutic preparations as important progress has been achieved in the development of engineered nanomaterials with high precision, responsiveness, and effectiveness for cancer therapy. Predictably, nanomaterials 
conjugated with precise functional groups target cancer cells and deliver appropriate encapsulated active materials. As innovative therapies for cancer treatment, polymeric nanomaterials, metallic nanoparticles, carbon-based materials, liposomes, and dendrimers have been developed to date, showing improved pharmacokinetic and pharmacodynamic profiles over traditional formulations due to their nanoscale size and special physicochemical features (Haroon Khan, et al. 2019) Figure 2.

\section{pH sensitivity of Nano drug delivery with a stabilized carrier at the cellular level}

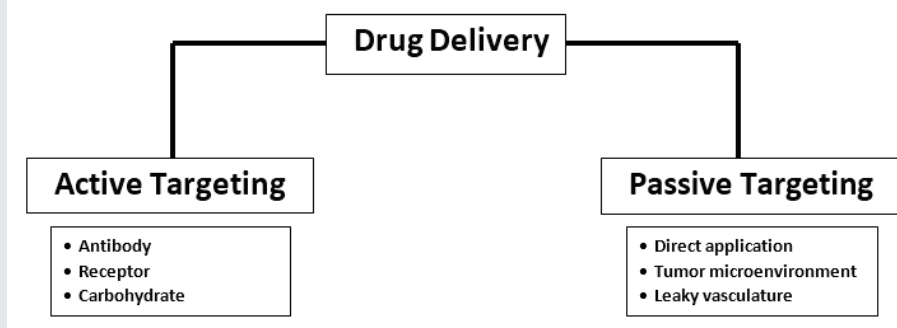

Figure 2: Application of drug delivery

As lysosomal enzymes easily terminate both the nanoparticle carrier and drugs around the cells, the carrier nanoparticles encounter the challenge of distributing drugs through the neoplastic cells and tissues. The colloidal carriers generally access the lysosomal region upon internalization as the carrier contents are impaired by hydrolytic enzymes. Therefore, whenever the encapsulated drug mimics a nucleic acid, the intracellular dissemination of the carrier is transformed [2]. As the $\mathrm{pH}$ is more acidic around the cancerous cells, any carriers that switch solubility at lower $\mathrm{pH}$ may be adopted in the attack and activate drug release [22]. The extracellular environment of blood cancers conversely is acidic and through their cellular compartments, there will be an altered $\mathrm{pH}$ level. Consequently, nanoparticles that are responsive to $\mathrm{pH}$ gradients are encouraging for the distribution of drugs and treatments as a $\mathrm{pH}$-sensitive nanoparticle comprises a shell with a center that reacts to $\mathrm{pH}$ as it alters the pattern of solubility [23]. Core-shelled nanoparticles with polymer frameworks are developed to be based on residual $\mathrm{pH}$ of 7.4 with their reduced critical temperature [23]. At low $\mathrm{pH}$, the resultant shift in LCST induces the core-shell nanoparticles to degrade with precipitation in acidic conditions in and around the cancerous cells, catalyzing the therapeutic activity [24]. A sustained approach for designing a $\mathrm{pH}$-responsive and release model for the cancer treatment was stated in several reports [25]. Their method employs solid non-hydrophilic nanospheres storing drug molecules that are coated with a $\mathrm{pH}$-responsive microsphere. A bioadhesive product was incorporated with the solid hydrophobic matrix of the nanospheres which is achieved by reacting paclitaxel with the hot melt of candelilla wax. That is, the $\mathrm{pH}$-sensitive matrix microsphere was produced by applying the drug/wax blend to an aqueous anionic polymer at a stable $\mathrm{pH}$ of 7.4 and solubilized $\mathrm{pH}$ of 6 and below creating a free-flowing dry powder consisting of 10 percent paclitaxel with the prepared suspension that was spray-dried by dispersing the microsphere at a lower $\mathrm{pH}$ with the cancerous tissue and the nanospheres as they distribute the drug over time [25]. In the case of their efficient endo-lysosomal recovery, biodegradable nanoparticles have been derived through copolymers of poly (d, l-lactide-co-glycolide). The mechanism behaved by specifically altering the substrate charge of these nanoparticles in the acidic endo-lysosomal cavity, enabling the nanostructures to react with the endo-lysosomal layer directly to the cytosol) [26]. For sustainable therapeutic impacts, these nanoparticles can distribute a variety of therapeutic agents especially deoxyribonucleic acid at a gradual rate [26]. Hence, scientists have invented $\mathrm{pH}$-responsive, thermo-responsive, and environmentally friendly nanoparticles for the application of nanotechnology in cancer therapy through the implantation of ecofriendly poly-(d, l-lactide) against methacrylic acid and $\mathrm{N}$-isopropyl acrylamide. The concentration of the drug which is hydrophobic with the easy cross of the plasma membrane in the target tissue may be appropriate for a delivery mechanism [27].

\section{Biochemistry of nanostructured targeting agents}

Nanocarriers including anticancer drugs, targeting substituents, and composites are engaged as targeting agents for cancer therapy with a spectrum of nano-carriers including the dendrimers, carbon nanotubes, liposomes nano-capsules, micelles, and nanospheres which covalently enclosed the therapeutic agents within the entrapped nanoparticles [28]. Liposomes are lipid bilayers where the center may be hydrophobic or hydrophilic where single bilayer lipid possesses a soluble center that encapsulates water-soluble drugs, while the other contains lipid-soluble drugs [28]. However, as macrophages rapidly nullify their activity, they are coated for balanced physiological conditions with an inert polymer matrix of Polyethylene Glycol (PEG) with liposomes [29]. In vivo research indicates that Hyaluronan (HA) coated liposomes optimize circulation time and improves the selection of HA receptor-expressing tumors [30]. The classes of liposomal treatment delivery in terms of passive and active selection can be accomplished as liposomal nanoparticles can be paired with either antibodies or appropriate drug delivery ligands with the benefits of being biodegradable, non-antigenic, and a high transport rate [31]. Dendrimers are three dimensional and treelike formations with a polyfunctional center from elements that are either synthetic or natural, such as amino acids, sugars, and nucleotides [32]. They are synthesized to preserve the desired shape and size by coordinated polymerization of the monomeric units due to their particular branching nature, several entities, including both hydrophobic and hydrophilic molecules for conjugation [33]. Through hydrophobic, hydrogen bonds, or chemical interconnections, they may also be filled with drugs by using cavities in their cores to deliver genes, medications, and anticancer agents. Micelles are circular entities where the central core is developed by molecules with a hydrophobic end aggregate and hydrophilic ends of other molecules in association with the core's surrounding liquid atmosphere as they are an appropriate medium for the distribution of nonaqueous drugs in their hydrophobic part [34]. Nanospheres are 
spherical particles, consisting of a matrix material where the drug is distributed uniformly by encapsulation or attachment with a surface that can be manipulated for targeting motives by the insertion of ligands or antibodies. Conversely, nanocapsules are like membranes with a central structure where a drug is enclosed with a polymeric surface wrapping the core [35]. In the shape of a hollow tube, nanotubes with fullerenes are a family of molecules with carbon as their atoms are trapped as receptors or ligands to be attached to their targeting surface [36]. To be water-soluble and activated, carbon nanotubes are modified for the connection to several active molecules like peptides, proteins, nucleic acids, and active therapeutic agents [37]. Poly (alkyl cyanoacrylates), poly (methylidene malonate), and polyesters such as poly (lactic acid), poly (glycolic acid), poly (e-caprolactone), and their copolymers are suitable polymers for nanoparticles synthesis [38]. In terms of biocompatibility and biodegradability, poly ( $\varepsilon$-caprolactone), glycolic acid (PGA), lactic acid (PLA) with their copolymers are the most extensively investigated [39].

\section{Recent methodologies for nano-based anticancer (leu- kemia) therapy}

Emulsion polymerization particle synthesis has been applied mainly for polymeric materials like Poly-Methyl Methacrylate (PMMA), Poly-Alkyl Cyanoacrylate (PACA), and Poly-Methylidene malonate (PMM). As the water-insoluble monomer is distributed in solution, polymerization is initiated and catalyzed by the addition of a chemical precursor and changes in physical conditions in terms of $\mathrm{pH}$ or gammaradiation in the presence or absence of emulsified stability surfactants [40]. The applications of the polymerized medium on preformed particles subsequently induce drugs to be stuck to the polymeric wall as polymer precipitation is the basis of the preparation of particles from preformed polymers. An aqueous system with or without a surfactant layer, allows the organic fraction of the polymer to be emulsified while at the second phase with the facilitation of particle deposition, the organic solvent is eliminated by methods such as salting out, evaporation, and diffusion with stirring at which the encapsulated substance needs to be at least partially soluble in an organic solvent [40]. Hence, the coating of hydrophilic bio compounds like peptides, proteins, or nucleic acids is thus a major drawback. Therefore, to enhance the formulation capacity of hydrophilic molecules, alternative processes such as the derivative of the hydrophilic substrate to form a complex structure that is hydrophobic have been established [40]. The typical way is to apply a double emulsion technique, where the hydrophilic compound in an aqueous system is initially emulsified into the polymer's organic solution and the main emulsion, with or without a surfactant, is then drained into a significant quantity of water. As regards the hydrophilic compounds, the double emulsion method retains good entrapment efficiency; nevertheless, the size of the particles is typically larger than the simplest emulsion mode. The spray-drying system, where the drug is absorbed or distributed inside an organic polymer solution to be atomized in a heated airflow as the solvent is rapidly volatilized and the dried nanoparticles are freely obtained. To increase the trapping performance of lipophilic compounds or to generate a sustained release mechanism, the nano-capsule technique offers several benefits just like the hydrophilic drugs, especially oily insulin suspensions. Nano-capsules can also be produced from alkyl cyanoacrylate monomer units through interfacial polymerization. In a solution of ethanol and oil, the drug product and the monomer are then dissolved or suspended with magnetic agitation [40].

Intracellular drug delivery applies to medicinal delivery agents inside the cell to particular compartments or organelles. The delivery of targeted intracellular drugs results in higher bioavailability of the therapeutic agent at the place of action, improves the pharmacological impact, and decreases the drug's side effects [34]. Drug-loaded nanoparticles carry drugs to the appropriate cellular targets inside the cell as a drug storehouse $[41,42]$.

It was reported that on the usage of $\mathrm{K} 562$ cells from human chronic myeloid leukemia as a model for the cytotoxicity assessment of pegylated gold nanoparticles (PEG-AuNPs) to explain the cell death mode. Also, they study peg-AuNPs intracellular localization and establish that at the period of $24 \mathrm{~h}$, they were internalized into the $\mathrm{K} 562$ cell cytoplasm and preferentially accumulated NPs in the cytoplasmic at 48-72 hr. The vacuoles and the mitochondria were disturbed. It was interesting to see that around the nuclear membrane the NPS had an increased strength. But they were not detected in the nuclei at $72 \mathrm{~h}[42,43]$.

The same K562 cell route can be cloned from chronic myelogenous human cells and identify the MDR leukemia in the cell line of K562/A02 by a repeated passage in nude mice and culture alternatively by selecting stepwise with a rising concentration of adriamycin Infection (ADM). The cells were then preserved in an RPMI 1640 medium with the necessary supplements. The two K562/sub-clones A02 and K562 cells were subcutaneously inoculated through the rear of Nude mice to develop xenograft models of human leukemia with MDR healthy. The combination of 5-bromotetrandrine was shown to be(5-BrTet), $\mathrm{Fe}_{3} \mathrm{O}$ magnetic nanoparticle and daunorubicin showed drug resistance reversal in vivo. It was proposed that 5-BrTetet be inhibited P-work GP's to accumulate anticancer drugs in the body. Synergistic effects were seen in a related study with the induction of magnetic nanoparticle $\mathrm{Fe}_{3} \mathrm{O}_{4}$ with daunorubicin. The Polylactic Acid (PLA) nanocomposites production by the electrospinning method has shown an increased accumulation of daunorubicin in the leukemic K562 cells. The drug permeation on the target $\mathrm{K}_{562}$ cells could efficiently facilitate these nanocomposites $[42,44]$.

The use of Nitrogen $(\mathrm{N})$ dopant elements to boost the photocatalytic activity of nanoparticles based on Titanium Dioxide ( $\left.\mathrm{TiO}_{2}\right)$ has been documented. The theTiO $\mathrm{n}$-doped nanoparticles were tested for their apoptotic effects. Compared with those of undoped $\mathrm{TiO}_{2}$ in both $\mathrm{K} 562$ cellsConditions of light and dark, it was found with the visible radiation on $\mathrm{N}$-dopedTiO2 triggered an intense inhibition of growth and apoptosis in cells of K562 with a fast dosage-dependent. The outcomes of apoptosis in treated-K5622 were also confirmed in the DNA fragmentation assay. After $48 \mathrm{~h}$, cells there were no 
inhibitory effects on the un-doped TiO2.On the growth of $\mathrm{K}_{562}$ cells and their viability. In conclusion, such nanoparticles can be of potential use in CML photocatalytic therapy $[42,45]$.

PVP-coated AgNPs of different dimensions in an antileukemia effect against different lines of human AML cells. In a dose-dependent way, AgNPs limited the viability of therapeutic isolates of AML patients. The authors investigated that the primary isolates of AML patients were higher; and that the cytotoxic effects of AML cells were stronger than normal hematopoietic cells. The biochemistry for AgNPs in preventing AML cell growth has been related to the release of oxygen radicals and silver ions to exert their cytotoxic effect. The dose was stated to play a critical role in cytotoxicity along with both the size and surface area of nanoparticles [42,46].

Mouse leukemia cell lines preserved in the DMEM culture are L1210 cells from the culture media for Cytotoxicity and cellular absorption of PLGA (ETO-PLGA NP) and PLGA-MPEG (ETO-PLGAMPEG NP) etoposide-loaded nanoparticles on L1210 cells [38]. For L121 cells, the IC50 values were 18.0, 6.2, and $4.8 \mu \mathrm{M}$ respectively for ETO, ETO-PLGA NP, and ETOPLGAMPEG NP. The higher cytotoxicity was due to increased cell absorption of the nanoparticles. By quantifying the percentage of fluorescence using 6-coumarin as the fluorescent marker in the nanoparticles, the cellular uptake of the nanoparticles was determined. To visualize the cellular absorption of the nanoparticles by L1210 cells, confocal microscopy was used [47].

\section{Diagnosis of leukemia using gold-nanoparticle}

Leukemia diagnosis and detection are difficult. Presently combinations of the available methods for leukemia diagnosis apply cytochemical studies of bone marrow and peripheral blood, including immunophenotyping by flow cytometry or microarray, and amplification by chain reaction with polymerase (PCR) of malignant cell mutations. Multiple antibody criteria for immunophenotyping. Samples for correct cell detection, which enhances the difficulty of both and the method's cost. Methods based on PCR do not explicitly detect Cells and before examination requires complex pretreatment. There is a here new technology for the rapid, easy, and economical diagnosis of whole-blood leukemia need to be developed. Also, precise and delicate Methods for the diagnosis of leukemia would make it easier for the selection of clinicians' successful treatment) [42].

These diagnostic problems may be solved by nanotechnology in the case of leukemia. Recently a new, rapid, homogeneous approach to testing fluorescence-based detection of leukemic cells in the whole blood established anisotropy [48]. The combined methodology provides the benefits of targetoriented near-infrared fluorescent nanoparticles Aptamersspecific to cells. The phase of fluorescence anisotropy gives a technique of rapid homogeneous recognition for leukemic detection without the need for complex separation steps, cells are in the entire blood. Aptamers have recently been recognized for diagnostic purposes. As reliable as antibodies, since they can easily be synthesized for Analysis, which does not require animal destruction [42].
Recently, there are reports of an introduction of a vastly selective, rapid, and sensitive DNA nano-sensor that could differentiate between the mismatched one-base oligonucleotide sequences for chronic lymphocytic leukemia detection. Centered on a Porphobilinogen Deaminase (PBGD) probe, this highly sensitive DNA sensor was constructed to detect a particular sequence of porphobilinogen deaminase genes highly associated with CLL cancer. A DNA probe of 25 nucleotides was modified with-SH was initially reacted chemically by selfassembly around the nanoparticles of gold. The detector was focused on the detection of sequence-specific DNA linked to chronic lymphocytic leukemia by Electrochemical Impedance Spectroscopy (EIS) [42].

\section{Application of gold nanoparticles for drug distribution}

The flexibility of gold-NPs been a critical drug delivery agent has been documented by numerous studies [49]. Without any safety and efficacy difficulties, drug delivery was very successful in moving the drug as nasal, mouth, eye, rectal, buccal, and inhalation are common distribution routes [49]. Due to the possible enzymatic destruction of most biomolecules, such as proteins, antibodies, peptides, genes, and vaccines, drugs were not able to be distributed through the aforementioned methods [50]. These macros and biomolecules, due to their molecular size, cannot be freely absorbed into the bloodstream as the key difficulties for protein and peptidebased drugs to be distributed with the nanoneedle array will therefore be the principal challenge. Consequently, to improve the reproducibility, specificity, reliability, and sensitivity in the targeted areas, several drug delivery techniques have been established. Therefore, in transmitting excited molecules through the cells, acoustic drug delivery is actively engaged with the ultrasound system [50]. The process of distributing thinfilm medications required readily disintegrating polymeric materials that could be easily assimilated through contact with the oral region [51]. Microemulsion for unique ouzo effects has been applied in the auto-micro emulsification drug distribution arrangement. The delivery process for neurological drugs could direct the therapies into the particular impaired nervous system) [52]. In nanomedicines, drug delivery systems have been a major encouragement as one of the critical and extensively employed resources in nanomedicine with the production of gold nano colloids.

The concept of involving gold nanoparticles was to advance the transportation of the drug in cancer therapies. Due to the hazardous activity against cancerous cells, the tumor necrosis factor-alpha (TNF-alpha), a cytokine, is an outstanding anticancer agent for therapeutic application (van Horssen, Ten Hagen, \& Eggermont, 2006) [53]. A nano-drug delivery concept was developed with TNF-alpha-conjugated PEG capped gold nanoparticles, which effectively inhibits tumor cellular damage with significant low toxicity [51]. The temperature and TNFalpha-conjugated PEG treated nanoparticles of gold from the study referenced above deduced a better therapeutic response compared to TNF-alpha-based treatment [51]. The cell proliferation was inhibited with TNF-alpha-conjugated PEG treated gold nanoparticle, administered intravenously with 
an acceptable dose and time. The blood supply to the cancer cells was blocked and was destroyed by the process of antiangiogenesis as particles were administered intravenously and no aggregation in the organs of healthy animals was observed [50]. Another strategy known as cryoinjury adopts ice ball vascular binding compounds which fully eliminate the tumor cells with no toxic impact [50]. In the effective delivery of TNF-alpha cancer cells, another gold-based precursor, labeled CYT-6091, was developed and administered into the bloodstream [54]. Methotrexate (MTX), an enzyme of dihydrofolate reductase inhibitor, has been used to treat different forms of cancer [48]. In a bid to explore the toxic and anti-tumor effects in vivo and in vitro, a composite product as MTX-gold nanoparticle was developed with a comparative analysis as the cancerous cells were disrupted by the MTX-gold hybrid, while the corresponding levels of free MTX exhibited no anticancer symptoms (Hagner \& Joerger, 2010). Notably, gold nanoshells with an enzyme embedded with horseradish peroxide (HRP) of hollow space as hydrogels have been invented through a soft chemical treatment for the delivery of photo thermally synthesized drugs [50]. As gold nanoshells maintain their stability, it is promising to rely on their physical parameters like the geometry on the intracellular absorption of gold nanoparticles, specifically when it has been ligands functionalized [55]. It was then important to be accurate and realistic to chelate the ligand with gold nanoparticles. Even when thiolated DNA bio-molecules are capable of being hybridized through the gold-sulfur bond to gold nanoparticles, the femtosecond impulse amplitudes of gold nanoparticles at a wavelength of $400 \mathrm{~nm}$ could eventually destroy the goldsulfur bond by elevating the energy absorption temperature of the particles [56]. Subsequently, PEG /peptides monolayers were developed on the nanoparticle surface to enhance the reliability of $\mathrm{Au}-\mathrm{NP}$ bio conjugates. Also, in high ionic intensity media, the resilience of bioconjugates, as a factor of particle diameter, PEG length, and monolayer structure, was examined. With increasing PEG length, the stability of NPs grew. The Au nanoparticle diameter was smaller and higher PEG mole fractions were reported. Modified Au-NPs with maximum PEG chain length above the surface raised the halflife by some hours that would be useful in cancer therapy [50]. Thus, without any obstacle, gold-NPs in drug delivery should be specific, effective, well targeted and directed to the site of interest.

In several cases around the world, leukemia, which results in death, is a form of cancer that typically includes blood cells and bone marrow. However, the most common form of childhood cancer is acute lymphoblastic leukemia with the chemotherapy of Dau, which is an anthracycline antibiotic, which is a recognized chemotherapeutic drug. Dau's clinical administration has been reduced especially in adolescents, due to its accumulated cardiotoxicity. There are reports of an aptamer with protein and tyrosine kinase-7 (PTK7), for Dau-specific delivery to Molt-4 cells [57]. The flow cytometry revealed that Molt-4 cells were effectively internalized to the aptamer-Dau complex but not to U266 cells. It is observed no major improvement in cell viability between the complex of Dau and aptamer-Dau treated with Molt-4 cells. Danesh et al updated polyvalent aptamer (PA)-Dau-Au-NP complexes in another study and tested their efficacy in human ALL T-cells (Molt-4, target) [57]. They loaded Dau (10.5 $\mu \mathrm{M})$ efficiently onto $1 \mathrm{~mL}$ of Au-NPs modified by PA. Dau was developed with a $\mathrm{pH}$-sensitive nature from the fabricated complex with immediate dissolution at $5.5 \mathrm{pH}$. The results of the obtained flow cytometry study showed that the complex of PA-Dau$\mathrm{Au}-\mathrm{NP}$ was internalized into target cells but not into nontarget cells. The findings of the MTT assay were compatible with the data for internalization [57]. Meanwhile, between only Dauand the complex of Apt-Dau-Au-NP, PA-Dau-Au-NP complexes retain weak cytotoxicity in $\mathrm{B}$ human lymphocyte myeloma cells and stronger cytotoxicity with Molt-4 cells [57]. With the use of PA's antisense, the PA-Dau-complex Au-NP cytotoxicity was practically inhibited. The developed drug delivery system had successful drug loading and tumor targeting capabilities, $\mathrm{pH}$-dependent drug release, and demonstrated controllable Dau delivery to tumor cells Figure 3 [57].

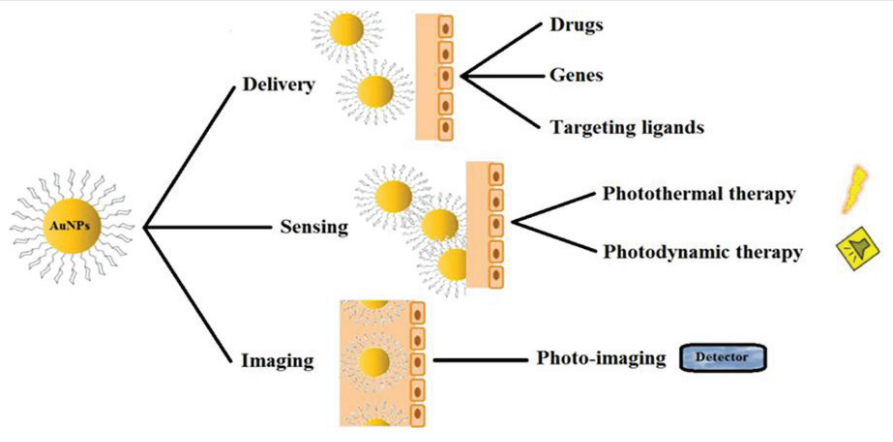

Figure 3: Gold nanoparticles in cancer diagnosis and treatment [44].

\section{Conclusion}

In certain ways, nanotechnology has already redefined cancer therapy and is transforming the pattern of treatment dramatically. It has had a significant effect on selective cancer cell detection, delivery of medications to the cells, and eliminating the limitations of traditional chemotherapeutics. Most formulations with nanotechnology (nanomedicine) have been unveiled to the market, as more are being investigated as clinical trials Are ongoing. Modern active or passive therapy, which can significantly increase the rate of survival, can substantially eliminate the side effects of conventional chemotherapy. As cancer is a dangerous and fatal infection, nanotechnology's commitment to the accurate treatment of life-threatening adverse effects would eventually lead to a positive life-saving intervention in clinical settings. Therefore, since gold NPs could be developed and combined with many functional agents that are biologically compatible and are readily integrated with biomaterials for the identification, imaging, diagnosis, and therapeutic provision for cancers and gene therapy. They have been demonstrated and confirmed, particularly the gold nanorods, as excellent agents for cancer drug delivery. Nevertheless, among all practical applications, the cytotoxic effect of gold nanoparticles, specifically through the cationic surfactant, should regularly be evaluated as 
it should be tackled with different surface modification methods, conserving the specific optical and physicochemical performances of gold NPs.

\section{References}

1. Deng R, Ji B, Yu H, Bao W, Yang Z, et al. (2019) Multifunctional gold nanoparticles overcome MicroRNA regulatory network mediatedmultidrug resistant leukemia. Scientific Reports 9: 1-11. Link: https://go.nature.com/2MZK7vH

2. Sutradhar KB, Amin M (2014) Nanotechnology in cancer drug delivery and selective targeting. International Scholarly Research Notices 1-12. Link: https://bit.ly/3pTUU9j

3. Tripathi PK, Tripathi S (2020) Dendrimers for anticancer drug delivery. In Pharmaceutical Applications of Dendrimers: Elsevier 131-150.

4. Allodji RS, Tucker MA, Hawkins MM, Le Deley MC, Veres C, et al. (2020) Role of radiotherapy and chemotherapy in the risk of leukemia after childhood cancer: An international pooled analysis. Int J Cancer. Link: https://bit.ly/3cR3YrR

5. Babovic S, Eaves CJ (2014) Hierarchical organization of fetal and adult hematopoietic stem cells. Exp Cell Res 329: 185-191. Link: https://bit.ly/3pYaYXK

6. Lopes JJMCC (2019) Potencial profilático e terapêutico de plantas e cogumelos em Oncologia-Leucemia e Linfoma. Universidade de Coimbra. Link: https://bit.ly/3twM3g9

7. da Silva Luz GV, Barros KVG, de Araújo FVC, da Silva GB, da Silva PAF, et al. (2016) Nanorobotics in drug delivery systems for treatment of cancer: a review. J Mat Sci Eng A 6: 167-180. Link: https://bit.ly/2MA52Wv

8. Mousa SA, Bharali DJ (2011) Nanotechnology-based detection and targeted therapy in cancer: nano-bio paradigms and applications. Cancers 3: 28882903. Link: https://bit.ly/3tAbPA3

9. Sutton D, Nasongkla N, Blanco E, Gao J (2007) Functionalized micellar systems for cancer targeted drug delivery. Pharm Res 24: 1029-1046. Link: https://bit.ly/3rwigXh

10. Quinteros DA, Bermúdez JM, Ravetti S, Cid A, Allemandi DA, et al. (2017) Therapeutic use of monoclonal antibodies: general aspects and challenges for drug delivery. In Nanostructures for Drug Delivery Elsevier 807-833. Link: https://bit.ly/3jsih7u

11. Tallury P, Kar S, Bamrungsap S, Huang YF, Tan W, et al. (2009) Ultra-small waterdispersible fluorescent chitosan nanoparticles: synthesis, characterization and specific targeting. Chem Commun (Camb) 2347-2349. Link: https://bit.ly/3oWNz7K

12. Muley H, Fadó R, Rodríguez-Rodríguez R, Casals N (2020) Drug uptake-based chemoresistance in breast cancer treatment. Biochem Pharmacol 177: 113959. Link: https://bit.ly/39Yhzf1

13. Anarjan FS (2019) Active targeting drug delivery nanocarriers: Ligands. NanoStructures \& Nano-Objects 19: 100370. Link: https://bit.ly/36U07q9

14. Navya P, Kaphle A, Srinivas S, Bhargava SK, Rotello VM, et al. (2019) Current trends and challenges in cancer management and therapy using designer nanomaterials. Nano Converg 6: 23. Link: https://bit.ly/3cR4oyr

15. Varki A (2007) Glycan-based interactions involving vertebrate sialic-acidrecognizing proteins. Nature 446: 1023-1029. Link: https://bit.ly/3tDA3t2

16. Wang HX, Xiong MH, Wang YC, Zhu J, Wang J (2013) N-acetylgalactosamine functionalized mixed micellar nanoparticles for targeted delivery of siRNA to liver. J Control Release 166: 106-114. Link: https://bit.ly/39W0pi4

17. Giusti I, D'Ascenzo S, Dolo V (2013) Microvesicles as potential ovarian cancer biomarkers. BioMed Research International 2013: 703048. Link: https://bit.ly/3pVgz7o
18. Fazio E, Gökce B, De Giacomo A, Meneghetti M, Compagnini G, et al. (2020) Nanoparticles Engineering by Pulsed Laser Ablation in Liquids: Concepts and Applications. Nanomaterials 10: 2317. Link: https://bit.ly/3aN2MmA

19. Lundquist $P$, Artursson $P(2016)$ Oral absorption of peptides and nanoparticles across the human intestine: Opportunities, limitations and studies in human tissues. Adv Drug Deliv Rev 106: 256-276. Link: https://bit.ly/3tEygnu

20. Zhao Z, Ukidve A, Krishnan V, Mitragotri S (2019) Effect of physicochemical and surface properties on in vivo fate of drug nanocarriers. Advanced Drug Delivery Reviews 143: 3-21. Link: https://bit.ly/3aN2XhK

21. Bourquin J, Milosevic A, Hauser D, Lehner R, Blank F, et al. (2018) Biodistribution, clearance, and long-term fate of clinically relevant nanomaterials. Adv Mater 30: 1704307. Link: https://bit.ly/36RUTLA

22. Liu Y, Wang W, Yang J, Zhou C, Sun J (2013) pH-sensitive polymeric micelles triggered drug release for extracellular and intracellular drug targeting delivery. Asian Journal of Pharmaceutical Sciences 8: 159-167. Link: https://bit.ly/3oYqvpc

23. Shen $Y$, Tang $H$, Radosz M, Van Kirk E, Murdoch WJ (2008) pH-responsive nanoparticles for cancer drug delivery. Methods Mol Biol 183-216. Link: https://bit.ly/3oXknof

24. Chandrasekhar P, Shahid-Mohammad S, Debnath S (2013) A review on latest trends in oncho nanotechnology. International Journal of Pharmaceutical Development and Technology 3: 106-109.

25. Fuchs $M$, Turchiuli $C$, Bohin $M$, Cuvelier ME, Ordonnaud $C$, et al. (2006) Encapsulation of oil in powder using spray drying and fluidised bed agglomeration. Journal of Food Engineering 75: 27-35. Link: https://bit.ly/3tMfLOK

26. Patil Y, Panyam J (2009) Polymeric nanoparticles for siRNA delivery and gene silencing. Int J Pharm 367: 195-203. Link: https://bit.ly/36Rv9ie

27. Gordon EM, Hall FL (2005) Nanotechnology blooms, at last. Oncology Reports 13: 1003-1007. Link: https://bit.ly/3rBM6FD

28. Pfeiffer H (2015) Hydration forces between lipid bilayers: A theoretical overview and a look on methods exploring dehydration. Subcell Biochem 71 69-104. Link: https://bit.ly/3tEHU9J

29. Gao D, Tang S, Tong Q (2012) Oleanolic acid liposomes with polyethylene glycol modification: promising antitumor drug delivery. Int J Nanomedicine 7: 3517-3526. Link: https://bit.ly/3oW9HPr

30. Arpicco S, Milla P, Stella B, Dosio F (2014) Hyaluronic acid conjugates as vectors for the active targeting of drugs, genes and nanocomposites in cancer treatment. Molecules 19: 3193-3230. Link: https://bit.ly/3rxJDMs

31. Malam Y, Loizidou M, Seifalian AM (2009) Liposomes and nanoparticles: nanosized vehicles for drug delivery in cancer. Trends Pharmacol Sci 30: 592 599. Link: https://bit.ly/3rCJ5F7

32. Szunerits S, Barras A, Khanal M, Pagneux Q, Boukherroub R (2015) Nanostructures for the inhibition of viral infections. Molecules 20: 1405114081. Link: https://bit.ly/39Y52Z5

33. Klajnert B, Bryszewska M (2001) Dendrimers: properties and applications. Acta biochimica pol 48: 199-208. Link: https://bit.ly/3jr6o1u

34. Salimi A, Makhmalzadeh BS, Esfahani G (2017) Polymeric micelle as a new carrier in oral drug delivery systems. Asian J Pharm 11: 704-711. Link: https://bit.ly/3oZyAdh

35. Venditti I (2019) Morphologies and functionalities of polymeric nanocarriers as chemical tools for drug delivery: A review. Journal of King Saud UniversityScience 31: 398-411. Link: https://bit.ly/2YRgShg

36. Thakral S, Mehta R (2006) Fullerenes: An introduction and overview of thei biological properties. Indian Journal of Pharmaceutical Sciences 68: 13-19. Link: https://bit.ly/3tF3b3o

Citation: Bhattacharjee R, Olabode HO, Victor O, Florence S (2021) Application of nano based drug delivery channel against leukemia chemotherapeutic resistance. Glob J Cancer Ther 7(1): 001-009. DOI: https://dx.doi.org/10.17352/2581-5407.000036 
37. Vardharajula S, Ali SZ, Tiwari PM, Eroğlu E, Vig K, et al. (2012) Functionalized carbon nanotubes: biomedical applications. Int J Nanomedicine 7: 5361-5374. Link: https://bit.ly/3cPFy1S

38. Gou M, Zheng X, Men K, Zhang J, Zheng L, et al. (2009) Poly ( $\varepsilon$-caprolactone)/ poly (ethylene glycol)/poly ( $\varepsilon$-caprolactone) nanoparticles: preparation, characterization, and application in doxorubicin delivery. J Phys Chem B 113: 12928-12933. Link: https://bit.ly/3tAdplt

39. Lopes MS, Jardini A, Maciel Filho R (2012) Poly (lactic acid) production for tissue engineering applications. Procedia Engineering 42: 1402-1413. Link: https://bit.ly/3oWaeAV

40. Patra JK, Das G, Fraceto LF, Campos EVR, del Pilar Rodriguez-Torres M, et al. (2018) Nano based drug delivery systems: recent developments and future prospects. Journal of nanobiotechnology 16: 71. Link: https://bit.ly/3a02wBq

41. Panyam J, Williams D, Dash A, Leslie-Pelecky D, Labhasetwar V (2004) Solid-state solubility influences encapsulation and release of hydrophobic drugs from PLGA/PLA nanoparticles. J Pharm Sci 93: 1804-1814. Link: https://bit.ly/3q3cjMl

42. Soni G, Yadav KS (2015) Applications of nanoparticles in treatment and diagnosis of leukemia. Mater Sci Eng C Mater Biol Appl C 47: 156-164. Link: https://bit.ly/2YVjLhi

43. Huang YC, Yang YC, Yang KC, Shieh HR, Wang TY, et al. (2014) Pegylated gold nanoparticles induce apoptosis in human chronic myeloid leukemia cells. Biomed Res Int 2014: 182353. Link: https://bit.ly/2Z88Wsl

44. Chen B, Cheng J, Wu Y, Gao F, Xu W, et al. (2009) Reversal of multidrug resistance by magnetic $\mathrm{Fe} 304$ nanoparticle copolymerizating daunorubicin and 5-bromotetrandrine in xenograft nude-mice. Int J Nanomedicine 4: 73-78. Link: https://bit.ly/39Y9qYb

45. Moosavi M, Khataee A, Moasses G (2013) Study of thephotocatalytic effects of nitrogen-doped titanium dioxide nanoparticles on growth inhibition and apoptosis induction in K562 cell line. Scientific Journal of Kurdistan University of Medical Sciences 18. Link: https://bit.ly/2LuvlY5

46. Guo D, Zhu L, Huang Z, Zhou H, Ge Y, et al. (2013) Anti-leukemia activity of PVP-coated silver nanoparticles via generation of reactive oxygen species and release of silver ions. Biomaterials 34: 7884-7894. Link: https://bit.ly/2N2pv6a
47. Yadav KS, Jacob S, Sachdeva G, Sawant KK (2011) Intracellular delivery of etoposide loaded biodegradable nanoparticles: cytotoxicity and cellular uptake studies. J Nanosci Nanotechnol 11: 6657-6667. Link: https://bit.ly/3cWT5F7

48. Hagner N, Joerger M (2010) Cancer chemotherapy: targeting folic acid synthesis. Cancer Manag Res 2: 293-301. Link: https://bit.ly/2N2VJ0X

49. Kandanapitiye MS, Gunathilake C, Jaroniec M, Huang SD (2015) Biocompatible D-penicillamine conjugated $\mathrm{Au}$ nanoparticles: targeting intracellular free copper ions for detoxification. Journal of Materials Chemistry B 3: 5553-5559. Link: https://rsc.li/39VsS7R

50. Das M, Mohanty C, Sahoo SK (2009) Ligand-based targeted therapy for cancer tissue. Expert Opin Drug Deliv 6: 285-304. Link: https://bit.ly/3jr7lkY

51. Bilal Q, Unhale S, Shelke S, Kale P, Sarode R, et al. (2019) A REVIEW ON MOUTH DISSOLVING FILMS

52. Dikpati A, Madgulkar A, Kshirsagar SJ, Bhalekar M, Chahal AS (2012) Targeted drug delivery to CNS using nanoparticles. J Adv Pharm Sci 2: 179-191. Link: https://bit.ly/36RxiL2

53. van Horssen R, Ten Hagen TL, Eggermont AM (2006) TNF-a in cancer treatment: molecular insights, antitumor effects, and clinical utility. Oncologist 11: 397-408. Link: https://bit.ly/2YSjnQz

54. Visaria R, Bischof JC, Loren M, Williams B, Ebbini E, et al. (2007) Nanotherapeutics for enhancing thermal therapy of cancer. Int J Hyperthermia 23: 501-511. Link: https://bit.ly/36QQGYH .

55. Kumar R, Maitra A, Patanjali P, Sharma P (2005) Hollow gold nanoparticles encapsulating horseradish peroxidase. Biomaterials 26: 6743-6753. Link: https://bit.ly/2YUdFgZ

56. David ME, Grumezescu AM (2019) Tailored Gold Nanoparticles for Cance Imaging and Therapy. Mater Int 1: 13-24. Link: https://bit.ly/3ruppD8

57. Jahangirian H, Kalantari K, Izadiyan Z, Rafiee-Moghaddam R, Shameli K, et al. (2019) A review of small molecules and drug delivery applications using gold and iron nanoparticles. International Journal of Nanomedicine 14: 1633-1657. Link: https://bit.ly/2Lx2fwE
Discover a bigger Impact and Visibility of your article publication with Peertechz Publications

Copyright: (c) 2021 Bhattacharjee R, et al. This is an open-access article distributed under the terms of the Creative Commons Attribution License, which permits unrestricted use, distribution, and reproduction in any medium, provided the original author and source are credited.

Citation: Bhattacharjee R, Olabode HO, Victor O, Florence S (2021) Application of nano based drug delivery channel against leukemia chemotherapeutic resistance. Glob J Cancer Ther 7(1): 001-009. DOI: https://dx.doi.org/10.17352/2581-5407.000036 